\title{
Impactos dos incentivos fiscais na inovação de grandes empresas: uma avaliação a partir da pesquisa Sondagem de Inovação da ABDI
}

Impacts of tax incentives on innovation of large companies: an evaluation based on ABDI innovation survey

\author{
Ulisses Pereira dos Santos (1) \\ Márcia Siqueira Rapini (1) \\ Philipe Scherrer Mendes (1) \\ (1) Universidade Federal de Minas Gerais
}

\begin{abstract}
Tax incentives are an instrument used to expand innovative efforts either quantitatively or qualitatively. In Brazil, fiscal incentives were broadened in 2005 with the Law of Good. This article analyzes the innovative efforts of companies in the ABDI Research Survey, comparing those that received tax incentives vis-à-vis those that did not receive, also controlling for the origin of capital. The analyzes carried out with Logit model indicated that the impacts of the tax incentives on the type of innovation performed vary according to the technological intensity of the sectors. But the tax incentives were not significant in relation to the origin of capital, indicating that they do not alter the innovation dynamics of the subsidiary companies.
\end{abstract}

\section{Keywords}

tax incentives, innovation, ABDI Innovation Survey, multinationals.

JEL Codes O31, O33, O38.

\section{Resumo}

Os incentivos fiscais são instrumentos utilizados para ampliar os esforços inovativos seja quantitativamente ou qualitativamente. No Brasil, os incentivos fiscais tiveram seu alcance ampliado a partir de 2005 com a Lei do Bem. Este artigo analisa o esforço inovador das empresas da Pesquisa Sondagem de Inovação da ABDI comparando as que receberam incentivos fiscais vis-à-vis com as que não receberam e também controlando pela origem do capital. As análises realizadas com modelo Logit indicaram que os impactos dos incentivos fiscais sobre o tipo de inovação realizada variam de acordo com a intensidade tecnológica dos setores. Mas os incentivos fiscais não foram significativos em relação à origem do capital, indicando que não alteram a dinâmica da inovação das empresas subsidiárias.

\section{Palavras-chave}

incentivo fiscal, inovação, Pesquisa Sondagem da ABDI, multinacionais.

Códigos JEL O31, O33, O38. 


\section{Introdução}

O processo inovativo caracteriza-se pela presença de incerteza que é intrínseca à sua dinâmica e ao processo competitivo de mercado (Metcalfe, 2003). A presença de incerteza e de risco tecnológico econômico dificulta o financiamento externo do processo de inovação (Arrow, 1962), em especial aquele proveniente do mercado. $O$ subfinanciamento das atividades de $\mathrm{P} \& \mathrm{D}$ e inovação decorre, também, da existência de assimetria de informação (Christensen, 1992) e da dificuldade de apropriação privada dos benefícios, visto que muitas vezes o conhecimento gerado é um bem público (Mazzucato; Pena; 2016). Outras características que remetem à necessidade de arranjos específicos de financiamento são: 1) resultados muitas vezes são ativos intangíveis de difícil mensuração (Nakamura, 1999); 2) conhecimento tácito inerente ao processo de inovação é indivisível (Williamson, 1986).

Em vista disso se coloca como fundamental a criação de instrumentos e mecanismos de financiamento diferenciados, seja pelas empresas, pelos mercados financeiros ou pela atuação dos governos (Mazzucato, 2014) para o financiamento ao processo de inovação. Com seu uso amplamente difundido em diversos países, os incentivos fiscais configuram uma das estratégias mais antigas para a ampliação dos esforços de inovação industrial, tanto em termos quantitativos quanto qualitativos. $O$ incentivo fiscal procura estimular a oferta de inovações por parte das empresas e são as próprias empresas que decidem como alocar os recursos no esforço inovador. Os incentivos fiscais reduzem o custo da inovação, supondo-se, portanto, que deveriam incentivar maior intensidade de esforço inovador, que poderia se traduzir em produtos com maior grau de novidade.

Os incentivos fiscais são utilizados no Brasil desde o início da década de 1990, no entanto, beneficiaram um número restrito de empresas. A "Lei do Bem" ampliou consideravelmente o número de empresas beneficiárias, mas os incentivos continuam concentrados nas regiões Sul e Sudeste (Matias-Pereira, 2015). No caso brasileiro, os incentivos fiscais tendem a beneficiar as empresas de maior porte visto que o mesmo incide sobre o lucro real.

Ainda são poucos os trabalhos destinados a avaliar o impacto dos incentivos fiscais nos esforços inovativos das empresas, seja ampliando (efeito adição) os gastos já realizados, ou incentivando que empresas não inova- 
doras comecem a inovar (Avellar; Alves, 2008; Calzolaio; Dathein, 2012; Zucoloto et al., 2017). Frente a isso, este artigo propõe, de forma pioneira, uma análise das empresas de grande porte no setor industrial brasileiro. São investigadas as empresas que participaram da pesquisa Sondagem da Inovação da ABDI. A Sondagem de Inovação é uma pesquisa que foi mantida pela Agência Brasileira de Desenvolvimento Industrial - ABDI, que visava, em sua primeira fase de realização, capturar trimestralmente informações acerca da atividade de inovação das empresas de grande porte atuantes em segmentos da manufatura no país (Libânio et al., 2019).

A partir do uso de dados da Sondagem de Inovação, este trabalho contribui para o debate acerca do impacto de incentivos fiscais na atividade inovadora no Brasil. Essa base de dados foi cruzada com dados do Ministério da Ciência, Tecnologia, Inovações e Comunicações (MCTIC) relativos aos incentivos fiscais concedidos às empresas localizadas no Brasil. Com isso foi possível acompanhar o esforço inovador de empresas de grande porte no período de 2010 a 2016, considerando os seus níveis de intensidade tecnológica, a origem do capital e o impacto do acesso aos benefícios fiscais. Em linhas gerais, o objetivo do presente artigo é captar, a partir de estimações econométricas, os impactos da obtenção de incentivos fiscais sobre as chances de inovação das empresas pesquisadas, controlando pela origem do capital e intensidade tecnológica dos setores. Nesse sentido, outro aspecto que diferencia este trabalho dos demais é relativo ao fato de este testar os impactos dos incentivos fiscais sobre as possibilidades de inovação de produto ou processo pelas firmas, e não sobre seus gastos em $\mathrm{P} \& \mathrm{D}$, como é feito pela maior parte da literatura sobre o tema no Brasil.

Além desta introdução, o artigo possui mais cinco seções. A segunda seção apresenta brevemente os objetivos, bem como as vantagens e desvantagens dos incentivos fiscais como política de fomento à inovação nas empresas. Ela também apresenta os avanços da política no Brasil no que concerne aos incentivos fiscais. A terceira seção apresenta a base de dados utilizada neste trabalho, a saber: a Pesquisa Sondagem de Inovação e a estratégia econométrica utilizada para a análise que se propõe, baseada num modelo Logit. A quarta seção apresenta um breve panorama sobre a captação de incentivos e a atividade de inovação entre as empresas da Sondagem de Inovação. A quinta seção apresenta os resultados para as estimações econométricas realizadas e a análise dos resultados, com vistas a avaliar os impactos dos incentivos fiscais sobre a dinâmica inovativa nas 
grandes empresas nas indústrias extrativa e de transformação no Brasil. A sexta seção conclui o trabalho.

\section{Incentivos fiscais: arcabouço teórico e a realidade brasileira}

Os incentivos fiscais são utilizados por governos de diversos países para incentivar que as empresas realizem atividades de $\mathrm{P} \& \mathrm{D}$. Essas isenções são realizadas de formas variadas pelos países, mas têm como objetivo premiar as empresas que fazem esforços inovativos (Bittencourt; Rauen, 2020). Ainda que exista uma variedade de isenções vigentes nos países, os incentivos fiscais tendem a beneficiar empresas estabelecidas que dispõem de recursos próprios para investir em atividades de inovação. Nesse sentido é a própria empresa que decide sobre seus investimentos em inovação, não havendo interferência do governo que fará a análise e isenção ex post, ou seja, após gasto e esforço já realizado pela empresa. Em vista disso, a literatura considera que este instrumento seria mais transparente (Hall, 2002) por não envolver escolhas do governo sobre quais atividades realizar ou em quais setores.

Avellar e Bittencourt (2017) sumarizam as limitações dos incentivos fiscais do ponto de vista da política de inovação a partir da literatura, sendo: 1) os incentivos fiscais não modificam a percepção de risco da empresa, alterando somente sua estrutura de custos; 2) os incentivos fiscais apenas reembolsam os gastos já realizados, não adianta recursos financeiros para as atividades de inovação nas empresas, privilegiando, portanto, as que já possuem recursos para investir; 3) os incentivos fiscais intensificam as atividades de inovação de empresas que já inovam; 4) assim, não sendo adequado para ampliar o número de novas empresas inovadoras.

No Brasil, os incentivos fiscais tiveram início no setor de informática com a Lei no 8.248 de 1991 conhecida como Lei de Informática. ${ }^{1}$ As empresas deveriam destinar um percentual de $5 \%$ do seu faturamento ao investimento em $\mathrm{P} \& \mathrm{D}$ e entre o mesmo, pelo menos, $2 \%$ teriam de ser

1 Os incentivos abrangiam: a) dedução de até $1 \%$ do imposto de renda da compra de ações novas de empresas brasileiras de capital nacional que tivessem a produção de bens e de serviços de informática como atividade principal; b) dedução de até $50 \%$ do imposto de renda das atividades de $\mathrm{P} \& \mathrm{D}$ realizadas; $\mathrm{c}$ ) isenção do IPI dos produtos fabricados no país. 
direcionados a $\mathrm{P} \& \mathrm{D}$ via convênios com universidades ou institutos de pesquisa. Em 2001 uma nova Lei de Informática foi sancionada (Lei no 10.176) introduzindo inovações na forma de conceder os incentivos, destacando-se: a) incentivos de IPI com redução progressiva; b) manutenção integral do incentivo para a Zona Franca de Manaus; c) criação do Fundo Setorial de Informática (CTInfo); d) vantagens para as regiões Nordeste, Norte e Centro-Oeste; e) isenção para PMEs; f) fim da cumulatividade dos mecanismos da Lei dentro da cadeia produtiva; g) melhor governança e transparência (Pacheco, 2007).

Entre 1993-2000 estima-se que os investimentos em P\&D das empresas beneficiárias dos incentivos da Lei de Informática tenham sido em torno de $\mathrm{R} \$ 3$ milhões, sendo $\mathrm{R} \$ 2$ milhões esforços de pesquisa na própria empresa. Os investimentos concentraram-se em poucas empresas: cerca de $83 \%$ dos benefícios concedidos foram concentrados em apenas $30 \mathrm{em}-$ presas, sendo que $61 \%$ dos benefícios foram para 10 empresas (Garcia; Roselino, 2004).

Os Programas de Desenvolvimento Industrial (PDTI) e o de Desenvolvimento Industrial Agropecuário (PDTA) foram criados pela Lei no 8.661 de 02/06/93 e até setembro de 1995 beneficiaram 27 programas de desenvolvimento tecnológico, abrangendo 26 empresas isoladas e um consórcio reunindo 40 empresas. Os programas contemplaram empresas do setor industrial de grande porte, incluindo a metalurgia e as indústrias mecânica, eletroeletrônica e química. Até este período, os dispêndios em $\mathrm{P} \& \mathrm{D}$ foram de US $\$ 538,6$ milhões e os incentivos concedidos foram de US\$ $\$ 158,4$ milhões.

De acordo com Pacheco (2007), entre 1994 e 2003, os incentivos usufruídos representaram 8,3\% dos investimentos realizados, sendo esta taxa em torno de 10\% no período de 1994-1999 e de 4,5\% entre 2000-2002. Avellar e Alves (2008) avaliaram o impacto do PDTI no gasto em inovação das empresas inovadoras no período de 2001-2003 a partir da Pesquisa de Inovação (2003) (PINTEC), encontrando que a participação no Programa determinou aumento de $190 \%$ nos gastos com atividades tecnológicas.

A Lei no 11.196 de 21/11/2005, conhecida como a "Lei do Bem", consolidou o uso de incentivos às atividades de $\mathrm{P} \& \mathrm{D}$ no Brasil, trazendo aperfeiçoamentos aos instrumentos já existentes. A Lei manteve a concessão dos benefícios a qualquer empresa que realizasse atividades de $\mathrm{P} \& \mathrm{D} .{ }^{2}$ Porém, permitiu $\mathrm{P} \& \mathrm{D}$, quando da determinação do lucro real para cálculo do IRPJ e da base de cálculo da Con- 
que os recursos pagos às MPEs ou aos inventores independentes para a realização de atividades de P\&D fossem deduzidos como despesas operacionais, sem que representassem receita para as MPEs. Ela, também introduziu a subvenção de um percentual da remuneração (até $40 \%$ ) de pesquisadores, mestres e doutores ocupados em atividades de inovação tecnológica. ${ }^{3}$

A Lei no 11.744 (2008) substituiu a depreciação acelerada pela integral na aquisição de máquinas, equipamentos, aparelhos e instrumentos novos a serem utilizados em atividades de inovação. Ademais, permitiu que empresas beneficiárias da Lei de Informática também fossem beneficiárias dos incentivos fiscais previstos na Lei anterior.

Calzolaio e Dathein (2012) avaliaram as empresas inovadoras da PINTEC que também receberam incentivos fiscais, comparando quatro edições da PINTEC: 2000, 2003, 2005 e 2008. Constataram que o incentivo fiscal é uma ferramenta eficaz no curto prazo para a intensificação das atividades de inovação das empresas previamente inovadoras, mas não é efetivo no que diz respeito ao objetivo de ampliação do número de empresas inovadoras. Da mesma forma, o uso de incentivos fiscais não se mostrou sustentável no apoio a projetos com maior risco, que necessitam de grande aporte de capital e envolvem custos de longo prazo, como aquisição de máquinas e equipamentos e contratação de pesquisadores.

Kannebley Jr. et. al. (2016) analisaram o impacto do incentivo fiscal nas empresas industriais brasileiras beneficiarias ${ }^{4}$ no período de 1999-2009, rejeitando a hipótese de efeito crowding-out do incentivo. Os resultados apontam que o aumento no dispêndio em P\&D proveniente do incentivo foi em média de $86 \%$ a $108 \%$, ao passo que o aumento no número de pessoal técnico foi de $9 \%$ em média. Contudo, o impacto foi significativo somente para as empresas de setores de baixa ou média intensidade tecnológica.

Kannebley Jr. e Porto (2012) avaliaram o impacto de incentivos fiscais na intensidade das atividades de Pesquisa, Desenvolvimento e Inovação

tribuição Social sobre o Lucro Líquido (CSLL). Tal percentual pode chegar a $80 \%$ dependendo do número de pesquisadores contratados pela empresa. Também é possível realizar a exclusão de $20 \%$ do total dos gastos realizados em $\mathrm{P} \& \mathrm{D}$ que foram objeto de patente concedida ou de cultivar registrado (MCT, 2008).

3 O percentual pode chegar a até $60 \%$ no caso de empresa estabelecida nas áreas de atuação das extintas SUDAN e SUDENE.

4 Os autores analisaram empresas da indústria de transformação, sendo a base de dados construída a partir da PINTEC e da PIA. As informações foram complementadas com informações da Relação Anual de Informações Sociais (RAIS), Secretária de Comércio Exterior (Secex) e do Ministério de Ciência, Tecnologia e Inovação (MCTI). 
(P\&D\&I) de 2001 a 2008. Os autores encontraram evidências de um impacto estatisticamente significativo e positivo para a Lei do Bem, em torno de $7 \%$ a $11 \%$. Por sua vez, o estudo indicou a ausência de impactos para a Lei de Informática. Os resultados foram determinados especialmente pelo comportamento das empresas de segmentos de média-baixa e média-alta intensidade tecnológica. Os resultados de Brigante (2017) sobre os efeitos da Lei de Informática, considerando três edições da PINTEC (2003-2005; 2005-2008; 2008-2011), foram na mesma direção, evidenciando não ser possível concluir pela eficácia da Lei de Informática no período analisado.

Zucoloto et al. (2017) avaliaram as empresas beneficiárias dos incentivos fiscais entre 2006 e 2013 e encontraram que a Lei do Bem resultou em impactos positivos e significativos de aproximadamente $17 \%$ nos dispêndios em $P \& D$ das empresas beneficiadas. Mas, nesse resultado identificaram também um efeito parcial de crowding-out, segundo o qual, parcela da ampliação dos gastos em $\mathrm{P} \& \mathrm{D}$ ocorreu substituindo o gasto público.

Colombo e Cruz (2018) analisaram os dados da PINTEC de 2008 e 2011 e encontraram que os incentivos fiscais influenciaram positivamente sobre os esforços de $\mathrm{P} \& \mathrm{D}$ dentre os investimentos em inovação das empresas. Foi observada uma elevação dos gastos com P\&D em cerca de R\$ 1,1 milhão na média. Ademais, encontraram que os incentivos fiscais fomentaram a contratação adicional de pesquisadores com diploma de graduação, mas não foi verificado impacto significativo para pessoal pós-graduado.

Por sua vez, Rocha e Rauen (2018) analisaram o período de 2010-2015 e encontraram que os incentivos fiscais não tiveram efeito relevante no investimento empresarial em $\mathrm{P} \& \mathrm{D}$, gerando não apenas um efeito substituição, mas também redução do investimento empresarial total em $\mathrm{P} \& \mathrm{D}$.

Em relação à origem do capital Zucoloto (2012) identificou significativa e crescente participação das empresas multinacionais como beneficiárias de incentivos fiscais, sendo essa participação, inclusive, superior em outros instrumentos de fomento à inovação, como subvenção econômica e financiamento reembolsável. Uma análise setorial realizada com dados de 2007 permitiu à autora inferir que a Lei do Bem não estaria incentivando novos investimentos em $\mathrm{P} \& \mathrm{D}$ de empresas multinacionais, visto que $60 \%$ da isenção de $\mathrm{P} \& D$ foi para subsidiárias do setor automobilístico.

Por sua vez, Oliveira (2018) investigou a subsidiária de uma empresa multinacional do setor de cosméticos que implantou um Centro de P\&D no Brasil estimulada pela Lei do Bem. A subsidiária brasileira se tornou 
produtora e exportadora de tecnologia global para o grupo. Esse caso exemplifica que a isenção da Lei do Bem, no caso de empresas multinacionais, pôde atuar reduzindo custos de inovação que já iriam ocorrer, mesmo na ausência do incentivo. Essa redução de custo pode ter gerado impactos positivos ao elevar gastos em $\mathrm{P} \& \mathrm{D}$ que as empresas já iriam realizar, funcionando como um "prêmio a inovações" (Zucoloto, 2012).

\section{Base de dados e metodologia}

Em busca da identificação dos impactos de incentivos fiscais sobre atividades tecnológicas das empresas industriais brasileiras, o presente trabalho estimará um modelo Logit tentando capturar, com a utilização de outras variáveis de controle, como empresas que obtiveram algum benefício fiscal no período analisado se diferenciam daquelas que não obtiveram. A análise será feita a partir do cruzamento de dados da pesquisa Sondagem de Inovação com informações do MCTIC sobre a concessão de incentivos fiscais.

Nossa hipótese é de que os incentivos fiscais afetam o desempenho inovativo das grandes empresas nacionais e multinacionais ${ }^{5}$ e que existe um gap entre o recebimento do benefício e o resultado inovativo. Como o processo inovativo apresenta diferentes esforços e diferentes estratégias quando se inova em produto ou se inova em processo, o trabalho abordará os dois tipos de inovações. Tentaremos, também, identificar como os diferentes esforços se manifestam quando as estratégias adotadas para a inovação visam o mercado ou possuem alcance apenas interno, para a firma.

\subsection{Base de Dados: A Pesquisa Sondagem de Inovação}

Entre os anos de 2010 e 2016, a Agência Brasileira de Desenvolvimento Industrial - ABDI - e a Fundação Instituto de Pesquisas Econômicas, Administrativas e Contábeis de Minas Gerais - IPEAD/UFMG - promoveram a pesquisa "Sondagem Trimestral de Inovação Tecnológica no Brasil", ou Sondagem de Inovação ${ }^{6}$. O objetivo principal dessa pesquisa foi captar e

5 A Pesquisa Sondagem de Inovação abrange apenas empresas do setor industrial com mais de 500 empregados.

6 Em 2016 o contrato com o IPEAD/UFMG foi encerrado e a pesquisa passou a ser realizada 
processar informações acerca do desempenho inovador de empresas industriais brasileiras para subsidiar o planejamento e a formulação de políticas setoriais. Com periodicidade trimestral, foram realizadas 26 edições da Sondagem de Inovação, permitindo uma cuidadosa avaliação do comportamento das empresas industriais no país (Rapini et al., 2018).

Ressalta-se que ao longo desse ciclo foram investigadas apenas as empresas de grande porte, as quais apresentariam uma maior dinâmica inovativa no Brasil, conforme apontado por pesquisas oficiais (IBGE, 2016). Sendo assim, o universo da pesquisa era formado por 1.485 empresas com mais de 500 funcionários nos segmentos da indústria extrativa (CNAEs 05 a 09) e da indústria de transformação (CNAEs 10 a 33) e a amostra por 304 empresas, a um nível de confiança de 95\% (Libânio et al., 2019).

A coleta dos dados se realizava por meio de um questionário on line aplicado às empresas, contendo perguntas acerca de sua atividade tecnológica no trimestre imediatamente anterior à realização da pesquisa. Este questionário era composto por 15 questões, as quais deveriam ser respondidas por representantes das empresas ocupados em atividades relacionadas a P\&D e inovação, sendo os seus principais tópicos relacionados a:

- A atividade de inovação das empresas (número de produtos e processos inseridos pela empresa no mercado e a existência de projetos de inovação ao longo do trimestre em questão),

- Ao esforço de inovação das empresas (dispêndio realizado e número de profissionais alocados em atividades de P\&D);

- Às razões para o investimento em inovação por parte das firmas (mercado, custos, especificações locais, entre outros).

$O$ desenho da pesquisa respeitava os padrões vigentes em surveys e pesquisas previamente estabelecidas em âmbitos nacional e internacional, o que tinha como propósito viabilizar a análise dos resultados à luz de outros levantamentos, sobretudo da PINTEC. Após a avaliação crítica dos dados pela equipe de pesquisadores, com o intuito de verificar possíveis erros de preenchimento nas respostas, os dados obtidos passavam por uma etapa de tabulação e análise para a posterior divulgação dos resultados (Libânio et al., 2019; Rapini et al., 2018).

Para o presente trabalho, a base de dados Sondagem da ABDI foi cruzada com outros dois bancos de dados. Primeiramente, entre as empresas 
da Sondagem foram identificadas as empresas que receberam incentivos fiscais, no período de 2007-2014, de acordo com informações disponibilizadas publicamente na internet pelo Ministério de Ciência, Tecnologia, Inovações e Comunicações (MCTIC). Tal cruzamento foi realizado por meio do número de CNPJ (Cadastro Nacional da Pessoa Jurídica) de cada uma das empresas. Foram identificadas entre as empresas da Sondagem de Inovação aquelas que constavam ou não na listagem de empresas contempladas com incentivos fiscais federais relativos ao esforço de inovação no período em questão. Os incentivos fiscais, diferentemente de outros instrumentos de fomento à inovação, são concedidos independentemente do tipo de atividade de inovação realizada pela empresa, sendo esta a responsável por decidir sobre as formas de utilização dos recursos obtidos. Ademais, as "isenções fiscais garantem alívio financeiro às empresas inovadoras e atuam no sentido de aumentar a renda disponível em períodos subsequentes de forma a estimular que elas continuem realizando tais atividades. Trata-se, portanto, de um instrumento que atua no estímulo à oferta de inovações pelas empresas" (Bittencourt; Rauen, 2020, p. 14). Ao inserir essa variável na análise, espera-se inferir se o incentivo foi capaz de induzir a um maior esforço inovador ou a inovações com maior grau de novidade.

Em seguida, as empresas da pesquisa da Sondagem foram classificadas de acordo com a origem de seu capital. Tal classificação foi possível a partir de informações extraídas da base de dados do Orbis. ${ }^{7}$ As empresas multinacionais possuem suas estratégias de inovação e $\mathrm{P} \& \mathrm{D}$ definidas na matriz, de forma que seus esforços inovativos, inicialmente, não dependeriam da existência de incentivos fiscais. Porém, a existência de incentivos fiscais ao reduzir o custo da inovação, pode aumentar os recursos disponíveis para inovação, podendo resultar em mais esforços inovadores ou com maior grau de novidade por parte das empresas multinacionais.

\subsection{Metodologia}

Pela proposta de identificar os condicionantes do processo inovativo, tan-

7 Do Bureau van Dijk Eletronic Publishing. Disponível em: <https://www.bvdinfo.com/>. 
to a inovação de produto quanto de processo, foram construídas quatro ${ }^{8}$ variáveis dependentes binárias com o valor " 0 " representando as empresas que não inovaram, e "1" representando as empresas que inovaram, com base no questionário trimestral da pesquisa. A partir daí, um conjunto de variáveis explicativas foi selecionado da Pesquisa Sondagem de Inovação com vistas a identificar possíveis condicionantes do processo inovativo brasileiro. Os dados utilizados foram:

1) Variável de interesse do trabalho, buscando estabelecer um paralelo entre as empresas que obtiveram e as que não obtiveram incentivo fiscal, com identificação da origem do capital das empresas:

- Variável binária do MCTIC sobre a concessão de subsídio, assumindo 1 para as empresas que obtiveram algum incentivo, e 0 para as que não obtiveram. ${ }^{9}$

- Variável binária da base de dados Orbis, assumindo 1 para empresas multinacionais, e 0 para empresas nacionais;

- Variável de interação entre multinacionais e subsídio, visando identificar potenciais diferenças na concessão de subsídios a empresas domésticas e multinacionais.

2) Variáveis de controle relacionadas à atividade inovativa das empresas:

- Dummy para empresas que tinham departamento de P\&D;

- Doutores empregados em atividades de P\&D;

- Dummy para empresas que declararem ter aumentado os gastos no último trimestre: gastos em inovação, gastos em capacidade física e gastos em P\&D interno;

3) Variáveis de controle sobre a percepção das empresas em relação ao processo inovativo e seus investimentos:

- Alta importância dos investimentos inovativos visando "abrir um novo mercado";

- Alta importância dos investimentos visando "fatia de mercado";

- Alta importância dos investimentos como resposta à "inovação de concorrentes";

- Alta importancia dos investimentos em resposta a "pressão de custos".

8 Inovação de Produto e Inovação de Processo para a firma e para o mercado.

9 Foram feitos testes de especificação que indicaram que a defasagem temporal do subsídio em três períodos foi a que apresentou resultado mais robusto em termos de impacto gerado pela política. 
Além das variáveis mencionadas, o modelo utiliza dummies setoriais e de ano tentando filtrar características específicas dos setores, mais ou menos propensos a inovação, e características dos anos, controlando particularidades que podem ter condicionado o desempenho inovador em resposta ao cenário nacional ou internacional.

A estimação é feita com base no modelo Logit, por máxima verossimilhança, em que um índice não observado $I_{i}$ é utilizado para representar a propensão a inovar das firmas industriais. Assume-se que tal índice esteja contido em um intervalo de menos infinito a mais infinito, com um nível crítico $I^{*}$ que determina uma inflexão em relação a inovar ou não inovar. Isto é:

$$
I N O V=\left\{\begin{array}{l}
1, \text { se } I_{i}>I^{*} \\
0, \text { se } I_{i} \leq I^{*}
\end{array}\right.
$$

portanto, o resultado inovativo pode ser escrito como uma função da propensão a inovar, como segue:

$$
I N O V_{i}=F\left(I_{i}\right)
$$

Considerando que $F\left(I_{i}\right)$, propensão a inovar, seja uma função linear de $k$, atributos das firmas $\left(X_{1}, X_{2}, \ldots . X_{k}\right)$, passamos a ter uma função do processo inovativo descrita como:

$$
I N O V_{i}=F\left(x_{i}^{\prime} \beta\right)
$$

Nesse sentido, pela estrutura da base de dados e a característica binária da variável dependente, serão estimadas diferentes especificações utilizando o modelo Logit binário, conforme Greene (2000) e Wooldridge (2002). Os resultados das estimações são interpretados com base no sinal e na significância dos coeficientes, os quais indicam aumento ou redução da probabilidade de a variável resposta ser 1 , ou seja, os resultados identificam características que contribuem para a firma inovar, ou diminuem a chance. 


\section{Incentivos fiscais e inovação: análise dos resultados}

Os resultados dos modelos econométricos são apresentados nas tabelas a seguir. Esta seção está dividida em duas subseções que apresentam, separadamente, os condicionantes dos esforço inovativo em produto e em processo. Os resultados serão discutidos com base na Razão de Chance, que indica a probabilidade de sucesso de o evento ocorrer (1 - inovar). Esse resultado de Razão de Chance pode ser convertido em um incremento percentual, que representa a probabilidade de uma alteração da categoria base em relação à categoria analisada, a partir de variações em características das firmas, controladas nas estimações. Assim sendo, as interpretações dos resultados são pautadas nas variações percentuais observadas a partir do cálculo a seguir: (Razão de Chance - 1) x 100. Para os resultados apresentados nas Tabelas 2 e 3, as variáveis de controle setorial e as dummies para os anos foram omitidas objetivando melhor visualização dos coeficientes de maior interesse deste trabalho. ${ }^{10}$ Os coeficientes originais estimados são apresentados no Anexo deste artigo, nas Tabelas A1 e A2.

Como já mencionado, outro ponto a se considerar é que para cada tipo de inovação, produto ou processo, foi feita a diferenciação segundo o grau de novidade do produto: produto/processo novo para o mercado ou produto/processo novo para a firma. Isso significa quatro diferentes especificações tentando capturar os condicionantes dos esforços inovativos: "inovação de produto para a firma", "inovação de produto para o mercado", "inovação de processo para a firma" e "inovação de processo para o mercado".

O objetivo do trabalho, de identificar a existência de impactos positivos na atividade de inovação das empresas, a partir do recebimento de incentivos fiscais concedidos pelo Governo Federal, demandou a identificação de uma melhor forma para capturar essa relação de dependência. Isso porque, por hipótese, espera-se que o resultado positivo da inovação não ocorra no mesmo período em que o benefício é concedido pelo Estado. Tentando verificar como essa determinação ocorre, algumas diferentes especificações, com diferentes defasagens temporais da variável incentivo, foram testadas visando identificar o melhor indicador para essa variável. Os testes sugeriram o uso da variável indicadora de recebimento

10 As tabelas completas, com os resultados de todas as variáveis utilizadas nas estimações estão disponíveis para consulta com os autores. 
do incentivo fiscal, defasada temporalmente em três anos tanto para os modelos que consideram a inovação de produto como também para os que consideram inovação de processo.

\subsection{Incentivos fiscais e a inovação de produto}

Os resultados apresentados na Tabela 1 identificam os determinantes da inovação de produto, para firma e para o mercado, considerando as empresas pesquisadas pela Sondagem de Inovação entre os anos de 2010 e 2016. Por uma opção metodológica, dada a identificação do efeito esperado do incentivo fiscal sobre o resultado inovativo, a variável de incentivo foi desagregada em quatro diferentes níveis de intensidade tecnológica, com vistas a avaliar os seus efeitos sobre cada um dos grupos setoriais obtidos (modelos II e IV). Tal desagregação tem como objetivo observar se é possível diferenciar o impacto dos incentivos fiscais em cada um desses estratos considerando o nível de intensidade tecnológica das empresas. A classificação aqui adotada toma como base aquela utilizada pela OCDE, ${ }^{11}$ permitindo, assim, a análise do padrão inovativo da indústria brasileira perante um regime tecnológico internacional, com base no que predomina em economias avançadas. Para tal, é utilizada uma correspondência entre a classificação tecnológica da OCDE e as divisões e grupos da CNAE (Cavalcante, 2014). Como é possível observar, comparando-se as estimações, os coeficientes obtidos para as demais variáveis utilizadas não apresentam grandes diferenças após tal desagregação.

Visto isso, a análise se concentrará nos resultados observados para as especificações que utilizam a desagregação da variável incentivo fiscal por nível de intensidade tecnológica. Quanto às inovações baseadas na introdução de produtos novos para a firma, mas não para o mercado, o modelo II indica que o incentivo fiscal defasado em três anos tem impactos positivos e significativos apenas para os setores considerados de média-alta intensidade tecnológica. Ou seja, para as empresas desse perfil, a captação de incentivos fiscais aumenta as possibilidades de introdução de produtos novos para elas. Segundo a Razão de Chance calculada a partir dos resultados das especificações, é observável que o incentivo fiscal 
amplia em $81 \%$ as chances de as empresas de setores de média-alta intensidade tecnológica introduzirem uma inovação desse tipo. A dimensão desses valores sugere que o incentivo é um importante determimante para a atividade inovativa nos segmentos de média-alta intensidade tecnológica no Brasil.

Tabela 1 Impactos dos incentivos fiscais sobre a inovação de produto das empresas da Sondagem de Inovação - Razão de Chance - 2010-2016

\begin{tabular}{|c|c|c|c|c|c|c|c|c|c|c|c|c|}
\hline & \multicolumn{6}{|c|}{ Para a Firma } & \multicolumn{6}{|c|}{ Para o Mercado } \\
\hline & \multicolumn{3}{|c|}{ Modelo I } & \multicolumn{3}{|c|}{ Modelo II } & \multicolumn{3}{|c|}{ Modelo III } & \multicolumn{3}{|c|}{ Modelo IV } \\
\hline & O.R. & & $\begin{array}{l}\text { Std. } \\
\text { Err. }\end{array}$ & O.R. & & $\begin{array}{l}\text { Std. } \\
\text { Err. }\end{array}$ & O.R. & & $\begin{array}{l}\text { Std. } \\
\text { Err. }\end{array}$ & O.R. & & $\begin{array}{l}\text { Std. } \\
\text { Err. }\end{array}$ \\
\hline Constante & 0,343 & *** & 0,051 & 0,303 & $* * *$ & 0,048 & 0,077 & $* * *$ & 0,016 & 0,068 & $* * *$ & 0,015 \\
\hline $\begin{array}{l}\text { Empresas } \\
\text { multinacionais }\end{array}$ & 0,913 & & 0,104 & 0,945 & & 0,110 & 1,609 & $* * *$ & 0,225 & 1,660 & $* * *$ & 0,237 \\
\hline $\begin{array}{l}\text { Incentivo às } \\
\text { multinacionais }\end{array}$ & 0,824 & & 0,150 & 0,799 & & 0,150 & 0,870 & & 0,196 & 0,853 & & 0,200 \\
\hline Incentivo concedido & 1,374 & $* * *$ & 0,148 & & & & 1,115 & & 0,146 & & & \\
\hline \multicolumn{13}{|c|}{ Incentivo - intensidade tecnológica } \\
\hline Baixa intensidade & & & & 1,310 & & 0,2351 & & & & 1,003 & & 0,2248 \\
\hline $\begin{array}{r}\text { Médio } \\
\text { baixa intensidade }\end{array}$ & & & & 1,146 & & 0,2239 & & & & 1,172 & & 0,2830 \\
\hline $\begin{array}{r}\text { Médio } \\
\text { alta intensidade }\end{array}$ & & & & 1,811 & *** & 0,2778 & & & & 1,442 & ** & 0,2663 \\
\hline Alta intensidade & & & & 0,810 & & 0,2299 & & & & 0,559 & & 0,2098 \\
\hline $\begin{array}{l}\text { Departamento } \\
\text { de P\&D }\end{array}$ & 1,156 & * & 0,0872 & 1,149 & * & 0,0866 & 1,065 & & 0,1000 & 1,055 & & 0,0993 \\
\hline Doutores em P\&D & 1,000 & & 0,0003 & 1,000 & & 0,0003 & 1,001 & $* * *$ & 0,0003 & 1,001 & $* * *$ & 0,0003 \\
\hline $\begin{array}{l}\text { Aumento dos gastos } \\
\text { em Inovação }\end{array}$ & 1,086 & & 0,1078 & 1,073 & & 0,1070 & 0,930 & & 0,1143 & 0,914 & & 0,1129 \\
\hline $\begin{array}{l}\text { Aumento dos gastos } \\
\text { em P\&D interno }\end{array}$ & 1,486 & $* * *$ & 0,1657 & 1,497 & $* * *$ & 0,1668 & 1,294 & * & 0,1763 & 1,306 & * & 0,1784 \\
\hline $\begin{array}{l}\text { Aumento dos gastos } \\
\text { em Capacidade Física }\end{array}$ & 1,496 & $* * *$ & 0,1260 & 1,510 & *** & 0,1278 & 1,318 & $* * *$ & 0,1318 & 1,334 & $* * *$ & 0,1339 \\
\hline \multicolumn{13}{|c|}{ Alta importância dos investimentos em Inovação } \\
\hline Abrir novos mercados & 1,188 & $* *$ & 0,1041 & 1,184 & * & 0,1041 & 1,560 & $* * *$ & 0,1549 & 1,558 & $* * *$ & 0,1552 \\
\hline $\begin{array}{l}\text { Ganhar participação } \\
\text { no mercado }\end{array}$ & 1,510 & $* * *$ & 0,1160 & 1,530 & $* * *$ & 0,1181 & 1,195 & * & 0,1162 & 1,206 & * & 0,1179 \\
\hline
\end{tabular}


Tabela 1 (continuação)

\begin{tabular}{|c|c|c|c|c|c|c|c|c|c|c|c|c|}
\hline & \multicolumn{6}{|c|}{ Para a Firma } & \multicolumn{6}{|c|}{ Para o Mercado } \\
\hline & \multicolumn{3}{|c|}{ Modelo I } & \multicolumn{3}{|c|}{ Modelo II } & \multicolumn{3}{|c|}{ Modelo III } & \multicolumn{3}{|c|}{ Modelo IV } \\
\hline & O.R. & & $\begin{array}{l}\text { Std. } \\
\text { Err. }\end{array}$ & O.R. & & $\begin{array}{l}\text { Std. } \\
\text { Err. }\end{array}$ & O.R. & & $\begin{array}{l}\text { Std. } \\
\text { Err. }\end{array}$ & O.R. & & $\begin{array}{l}\text { Std. } \\
\text { Err. }\end{array}$ \\
\hline $\begin{array}{l}\text { Inovação de } \\
\text { concorrentes }\end{array}$ & 1,207 & $* *$ & 0,0974 & 1,216 & ** & 0,0984 & 0,993 & & 0,0973 & 1,001 & & 0,0984 \\
\hline Pressão de custos & 1,004 & & 0,0758 & 1,006 & & 0,0760 & 1,185 & * & 0,1148 & 1,195 & $*$ & 0,1163 \\
\hline Dummy-Ano & Control & & & & & & Contro & & & & & \\
\hline \multicolumn{13}{|c|}{ Dummy CNAE 2.0 - Divisão } \\
\hline $\begin{array}{l}\text { Número de } \\
\text { observações }\end{array}$ & 3898 & & & & & & & & & 3919 & & \\
\hline Pseudo R2 & 0,068 & & & 0,072 & & & 0,045 & & & 0,046 & & \\
\hline
\end{tabular}

Fonte: Elaboração própria com base na Pesquisa Sondagem de Inovação (2010-2016).

Nota: ${ }^{* * *}$ significativo a $1 \%,{ }^{* *}$ significativo a $5 \%$ e ${ }^{*}$ significativo a $10 \%$.

Por outro lado, para os segmentos de baixa, média-baixa e alta intensidades tecnológicas a captação de incentivos fiscais não apresentou coeficientes significativos. Com isso, é possível afirmar que o impacto positivo e significativo dos incentivos fiscais, capitado pela estimação que agrega todos os níveis de intensidade tecnológica, tem um importante componente setorial. Sendo assim, só é possível afirmar que os resultados esperados, a saber o impacto positivo dos incentivos fiscais sobre a inovação, ocorrem no caso das empresas de média-alta tecnologia investigadas pela Sondagem de Inovação. Destaca-se que entre os setores classificados como de média-alta tecnologia estão alguns como a produção automotiva, a indústria química, a produção de máquinas e de equipamentos elétricos (Cavalcante, 2014). Setores, portanto, com intensidade em capital e com altos custos associados ao processo de desenvolvimento tecnológico, mas que apresentam destaque na estrutura industrial brasileira.

Quanto a outras variáveis de controle, observa-se que a existência de um departamento formalizado de $\mathrm{P} \& \mathrm{D}$ contribui para as possibilidades de inovação das empresas investigadas, embora o coeficiente seja válido apenas a $10 \%$ de significância. Na mesma linha, o aumento nos gastos com $\mathrm{P} \& \mathrm{D}$ interno e dos investimentos em capacidade física instalada também ampliam as chances de inovações baseadas na introdução de produtos novos para as empresas. 
Quanto às motivações para o investimento em inovação, percebe-se que a busca pela abertura de novos mercados e pela ampliação da participação no mercado de atuação impactam positivamente nas chances de inovação das empresas, quando se considera a introdução de produtos novos para elas, mas com similares já existentes. A reação à inovação de concorrentes também figura como uma variável que induz as ampliações nas chances de inovar das empresas pesquisadas. Destaca-se, ainda, que as variáveis relativas à origem do capital das firmas não geraram coeficientes significativos, considerando tanto o modelo I quanto o II. Nesse sentido, a origem do capital não parece relevante para a introdução de produtos novos para o mercado por parte das empresas aqui avaliadas, tampouco a obtenção de incentivos fiscais por empresas multinacionais, variável que também apresentou coeficiente não significativo.

Para as especificações que consideram a introdução de produtos novos para o mercado brasileiro (modelos III e IV), também é observável que os incentivos fiscais ampliam as chances de inovação das empresas pesquisadas. Contudo, tais impactos se concentrariam, novamente, apenas nos setores de média-alta intensidade tecnológica, como indica o modelo IV. Para essa especificação, os impactos dos incentivos sobre as empresas de baixa, média-baixa e alta intensidades tecnológicas não foram significativos, assim como nos modelos anteriores. Para as empresas engajadas em setores de média-alta intensidade tecnológica, a captação de incentivos fiscais amplia em $44 \%$ as chances de introdução de produtos novos para elas.

De forma distinta ao observado nos modelos I e II, para os modelos III e IV, a variável indicadora da origem do capital das empresas apresenta coeficiente positivo e significativo. Nesse sentido, tem-se que empresas multinacionais seriam mais propensas a introduzirem produtos novos para o mercado brasileiro, envolvendo-se, portanto, em inovações com maior grau de incerteza. O cálculo da Razão de Chance indica que empresas controladas por capitais estrangeiros teriam $66 \%$ mais chances de introduzirem produtos novos para o mercado nacional que empresas controladas por capitais domésticos. Deve-se considerar que as subsidiárias de multinacionais atuando no Brasil apresentam importante representatividade no que tange ao esforço interno em inovação, figurando em alguns seguimentos como os principais protagonistas do desenvolvimento tecnológico doméstico (Zucoloto; Cassiolato, 2013). Destacam-se setores como o automobilístico, a produção de bens de capital e de telecomunicações, 
para os quais a participação das empresas estrangeiras é fundamental no que tange a P\&D e inovação (Queiroz; Carvalho, 2005).

Cabe destacar que em algumas situações esses produtos novos para o mercado brasileiro introduzidos por subsidiárias de multinacionais são desenvolvidos em seus países de origem, onde se encontram os seus centros de P\&D. Pois, apesar da crescente internacionalização das atividades tecnológicas das empresas multinacionais, o seu núcleo se mantém localizado nos centros de decisão dessas empresas (Zucoloto; Cassiolato, 2013). Por isso, na maior parte das vezes, a participação das subsidiárias localizadas em economias como a brasileira acaba por se concentrar em atividades relacionadas a adequações de produto ao mercado local ou ainda àquelas de menor complexidade tecnológica (UNCTAD, 2019). Assim, mesmo que as MNCs apresentem destaque quando da introdução de produtos novos para o mercado brasileiro, cabe considerar que suas subsidiárias localizadas no país tendem a apresentar pouca participação no desenvolvimento desse tipo de inovação, o que, por sua vez, expõe uma das fragilidades do sistema nacional de inovação, a depêndencia da tecnologia internacionalmente desenvolvida.

O fato de a concessão de incentivos fiscais para empresas multinacionais não apresentar coeficiente significativo condiz com evidências previamente observadas. Zucoloto (2012) observa que subsidiárias de multinacionais atuando no Brasil demonstram menor acesso a mecanismos de incentivo fiscal para a inovação, sendo que, para a autora, a atividade de $\mathrm{P} \& \mathrm{D}$ dessas empresas independe de políticas de incentivos.

Assim como nas especificações anteriores, é observável que a ampliação dos gastos em P\&D e do investimento em capacidade instalada apresenta influência positiva sobre a capacidade de inovar das empresas. No entanto, para a inovação baseada na introdução de produtos novos para o mercado nacional, a presença de funcionários com o título de doutorado e empregados exclusivamente em atividades de $\mathrm{P} \& \mathrm{D}$ se colocou como um determinante com coeficente positivo e significativo, tanto para o modelo III quanto para o modelo IV. Esse achado indica que para a introdução de produtos novos para o mercado, a presença de maiores capacitações internas às firmas é um determinante fundamental, mesmo que não exista formalmente um departamento de $\mathrm{P} \& \mathrm{D}$ interno na firma. Resultados semelhantes foram encontrados em Porto et al. (2012). 
A avaliação dos aspectos considerados importantes para as empresas em sua decisão de inovação indica que a busca por maior participação no mercado seria a motivação para a introdução de produtos novos para o mercado que mais amplia as chances de inovação.

\subsection{Inovação de processo}

Os resultados apresentados na Tabela 2 identificam os impactos dos incentivos fiscais sobre a inovação de processo, nos mesmos moldes da subseção anterior, considerando processos novos para o mercado como também aqueles novos apenas para a empresa, mas já existentes no mercado. Utiliza-se novamente o indicador de Razão de Chance com vistas a interpretar as evidências apresntadas pelos modelos estimados, estando os coeficientes originais disponíveis na Tabela A2 do apêndice deste trabalho.

Assim como no caso da inovação de produto, foi realizada a desagregação da variável que indica o recebimento de incentivos fiscais em quatro diferentes níveis de intensidade tecnológica visando identificar como os seus impactos se comportam em cada um dos grupos setoriais aqui considerados. Destaca-se, ainda, que essa variável foi defasada em três anos, conforme pontuado acima. Dessa forma, busca-se avaliar como o incentivo obtido pelas empresas três anos antes impacta sobre sua inovação de processo no momento da pesquisa.

Tabela 2 Impactos dos incentivos fiscais sobre a inovação de processo das empresas da Sondagem de Inovação - Razão de Chance - 2010-2016

\begin{tabular}{|c|c|c|c|c|c|c|c|c|c|c|c|c|}
\hline & \multicolumn{6}{|c|}{ Para a Firma } & \multicolumn{6}{|c|}{ Para o Mercado } \\
\hline & \multicolumn{3}{|c|}{ Modelo I } & \multicolumn{3}{|c|}{ Modelo II } & \multicolumn{3}{|c|}{ Modelo III } & \multicolumn{3}{|c|}{ Modelo IV } \\
\hline & O.R. & & $\begin{array}{l}\text { Std. } \\
\text { Err. }\end{array}$ & O.R. & & $\begin{array}{l}\text { Std. } \\
\text { Err. }\end{array}$ & O.R. & & $\begin{array}{l}\text { Std. } \\
\text { Err. }\end{array}$ & O.R. & & $\begin{array}{l}\text { Std. } \\
\text { Err. }\end{array}$ \\
\hline Constante & 0,480 & *** & 0,071 & 0,463 & $* * *$ & 0,072 & 0,105 & $* * *$ & 0,0223 & 0,111 & $* * *$ & 0,0249 \\
\hline $\begin{array}{l}\text { Empresas } \\
\text { multinacionais }\end{array}$ & 0,880 & & 0,101 & 0,905 & & 0,105 & 1,525 & $* * *$ & 0,2434 & 1,508 & $* *$ & 0,2441 \\
\hline $\begin{array}{l}\text { Incentivo às } \\
\text { multinacionais }\end{array}$ & 1,339 & & 0,245 & 1,222 & & 0,230 & 0,757 & & 0,1906 & 0,723 & & 0,1856 \\
\hline Incentivo concedido & 0,911 & & 0,096 & & & & 1,128 & & 0,1637 & & & \\
\hline
\end{tabular}

(continua) 
Tabela 2 (continuação)

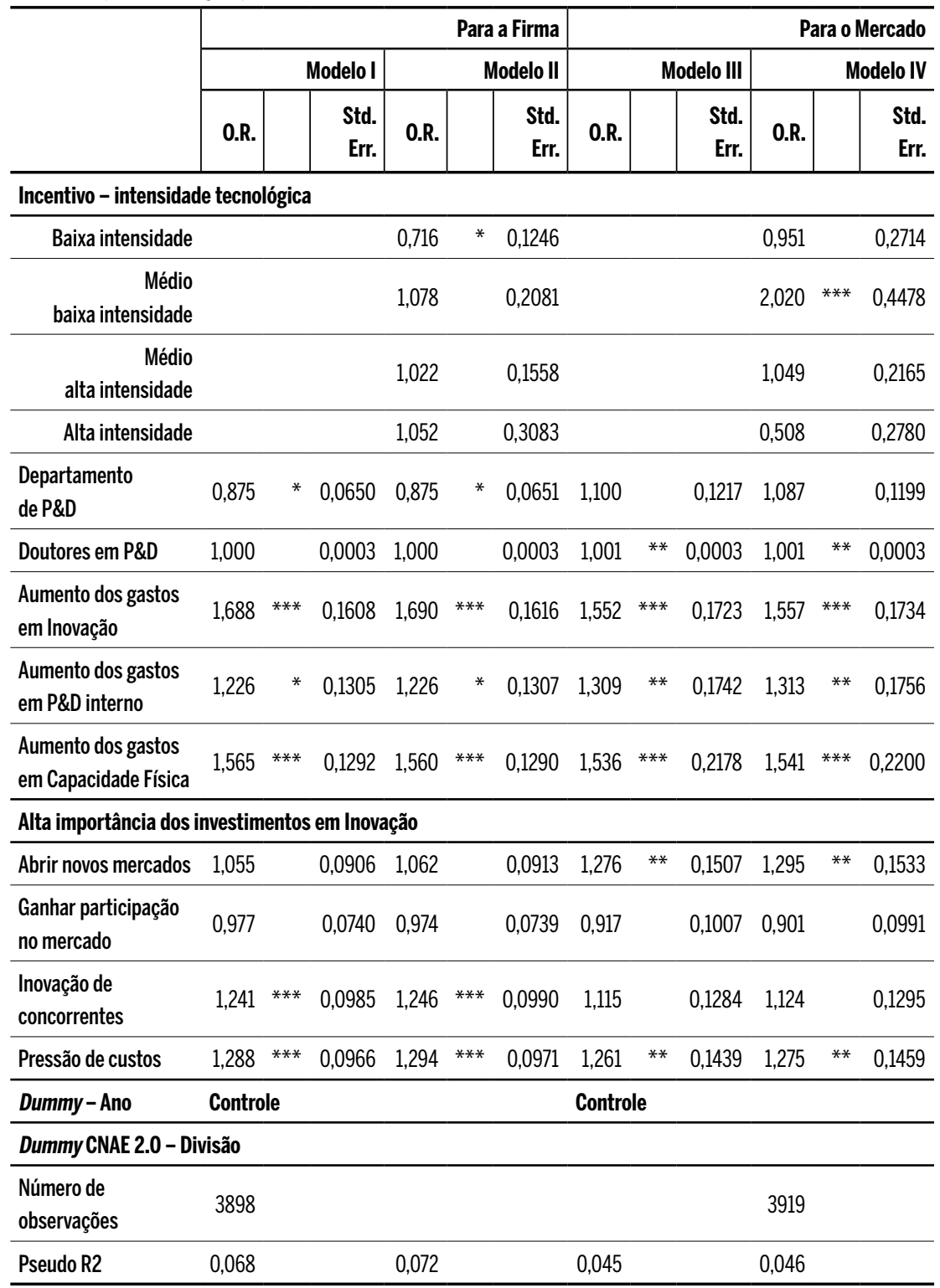

Fonte: Elaboração própria com base na Pesquisa Sondagem de Inovação (2010-2016).

Nota: ${ }^{* *}$ significativo a $1 \%$; ${ }^{* *}$ significativo a $5 \%$; e ${ }^{*}$ significativo a $10 \%$.

A especificação que considera a introdução de processos novos para as firmas, mas não para o mercado, não apresenta efeitos significativos do in- 
centivo fiscal de forma agregada (modelo I) sobre as empresas pesquisadas. A desagregação por intensidade tecnológica da variável incentivo (modelo II), por sua vez, apresenta um coeficiente significativo, porém, negativo para os setores de baixa intensidade tecnológica. Para os demais níveis de intensidade tecnológica não houve significância para os coeficientes, assim como para a variável referente à origem do capital controlador das empresas consideradas.

As variáveis que tendem a acrescer as chances de inovação das empresas, no que tange à adoção de processos novos para elas, mas já existentes no mercado, são as relativas aos gastos em inovação de forma geral, aos gastos em $\mathrm{P} \& \mathrm{D}$ e à ampliação da capacidade instalada. As pressões de custos e a inovação de concorrentes também ampliam as chances desse tipo de inovação nas empresas, estando em acordo com o tipo de inovação considerado como variável dependente.

Observa-se, ainda, a presença de sinais negativos para os coeficientes da variável referente à existência de departamentos internos de $\mathrm{P} \& \mathrm{D}$ à firmas, nos modelos I e II. Tal resultado indica, portanto, que a presença de departamentos internos de $\mathrm{P} \& \mathrm{D}$ nas firmas reduz as suas chances de inovação sustentada na introdução de processos novos para a empresa, mas não para o mercado, em $22 \%$ segundo os dois modelos. Esse resultado sugere que empresas que fazem $\mathrm{P} \& \mathrm{D}$ internamente tendem a priorizar a adoção de processos produtivos novos para o mercado. Em outros termos, a estrutura interna de $\mathrm{P} \& \mathrm{D}$ reduz as chances de essas empresas incorporarem processos já difundidos no mercado nacional.

No caso da introdução de processos novos para o mercado, o modelo III, no qual não há desagregação por nível de intensidade tecnológica, não apresentou signficância para o coeficiente da variável "incentivos". No entanto, no modelo IV, que desagrega os impactos dos incentivos por intensidade tecnológica das empresas, observa-se que tal variável tem coeficiente positivo e significativo apenas quando se considera empresas de média-baixa intensidade tecnológica. Tal resutlado indica que as empresas atuantes nesses segmentos teriam sua chance de inovar com a introdução de processos novos para o mercado acrescida em mais que $100 \%$, a partir do acesso a esse tipo de benefício fiscal. Nesse sentido, considerando as empresas investigadas pela Sondagem de Inovação, os resultados observados para inovação de processo, seja novo para a firma ou novo para o mercado, indicam que os incentivos fiscais fomentaram a inovação apenas em 
setores com maior grau de maturidade tecnológica, caso dos segmentos de baixa e média-baixa tecnologia, apontando novamente no mesmo sentido que estudos anteriores (Kannebley Jr. et al. 2016).

Destaca-se que, assim como visto na inovação de produto, a variável referente à origem do capital das empresas somente foi significativa para as espcificações que consideram processos novos para o mercado nacional. Sendo assim, os sinais positivos para os seus coeficientes nos modelos III e IV sugerem que empresas multinacionais teriam maior probabilidade de introdução de inovações com maior grau de novidade para o mercado doméstico. Tal resultado corrobora observações prévias que apontam a preponderância de subsidiárias de empresas multinacionais no Brasil quanto à aquisição de máquinas e equipamentos, o que representa uma importante fonte de inovação em processos no país (Zucoloto; Cassiolato, 2013). Destaca-se que a aquisição de máquinas e equipamentos ocorre muitas vezes via importação e que, consequentemente, representa a absorção de novos padrões produtivos pelas empresas no país. Por isso, esse esforço inovativo resultaria na introdução de processos novos para o mercado nacional. Deve-se ressaltar, ainda, que as conexões das subsidiárias de multinacionias no mercado internacional facilitariam o seu acesso a processos ainda não difundidos no Brasil.

Por outro lado, o incentivo fiscal concedido às empresas de origem multinacional não se mostrou significativo estatísticamente, tal qual observado para a inovação de produto. Esse quadro reforça o entendimento de que a decisão de $\mathrm{P} \& \mathrm{D}$ e inovação dessas empresas não é diretamente influenciada pelas políticas domésticas de incentivo fiscal (Zucoloto, 2012).

Destaca-se, ainda, que além dos gastos em inovação, $\mathrm{P} \& \mathrm{D}$ e capacidade física, a presença de funcionários com o título de doutor se coloca como um determiante positivo para a inovação com processos novos para o mercado. Considerando as motivações para o investimento em inovação, a abertura de novos mercados e as pressões de custos foram os aspectos que mostraram significância estatística, sendo, portanto, os elementos que afetam positivamente a introdução de novos processos.

\section{Considerações finais}

O presente trabalho se propôs a avaliar os impactos das políticas de incentivo fiscal sobre a atividade de inovação de empresas de grande porte 
atuantes nos setores da indústria extrativa e de transformação no Brasil, considerando o período entre 2010 e 2016. Para tal, foram realizados testes econométricos com vistas a identificar os impactos desses instrumentos de política pública sobre as chances de inovação das empresas pesquisadas pela Sondagem de Inovação. Com isso, utilizou-se pela primeira vez, e para esse fim, a referida base de dados, que se destaca por apresentar um compilado de informações sobre atividades tecnológicas na indústria doméstica de forma contínua ao longo de um intervalo de seis anos. $O$ uso desses dados constitui uma contribuição em relação a outros estudos nessa linha, uma vez que permitiu a avaliação dos impactos dos incentivos obtidos por empresas industriais sobre a sua inovação em produto e processo, enquanto a maior parte da literatura avalia a dinâmica de tais impactos sobre o P\&D ou outras formas de esforço inovativo. Logo, avaliam-se neste trabalho os resultados efetivos da política de incentivos a partir da dinâmica inovativa das empresas. Ademais, as análises aqui realizadas procuraram investigar a atuação das empresas de acordo com a origem do capital no processo de inovação doméstico.

Os resultados observados indicaram que os impactos dos incentivos guardam relação com o grau de intensidade tecnológica dos setores nos quais as empresas pesquisadas atuam. Nesse sentido, observou-se que para a inovação de produto, seja para o mercado brasileiro ou para a firma, a introdução de produtos novos é positivamente impactada pela obtenção de incentivos fiscais apenas para setores de média-alta intensidade tecnológica. Por sua vez, a estimação que considera a introdução de processos novos para o mercado indica que os incentivos impactam positivamente na atividade de inovação de empresas engajadas em setores de média-baixa intensidade tecnológica. Observou-se, ainda, nesse caso, que os incentivos tendem a induzir as empresas a priorizarem a introdução de processos novos para o mercado, em detrimento da introdução de processos já existentes (imitação). Esse resultado indica que as empresas contempladas com os incentivos fiscais tendem a inovar com processos que tenham maior grau de novidade sobre o mercado brasileiro.

Tais resultados sugerem que os impactos das políticas de incentivos fiscais ocorrem de forma diferenciada em termos do grau de intensidade tecnológica dos setores. Trata-se de um aspecto que deve ser considerado quando da formatação desse tipo de estratégia de política industrial, de modo a se alcançar o design mais eficiente para a concessão de incentivos 
para a indústria. Em outros termos, faz-se necessário questionar se os reais impactos desse tipo de benefício justificam sua adoção para todo tipo de indústria, ou se somente para aquelas que apresentem maior retorno.

Em termos da origem do capital, as estimações não trazem resultados significantes estatisticamente. Assim, não há indícios de que os incentivos fiscais são efetivos para a alteração da dinâmica da inovação em subsidiárias de multinacionais no país. Tal resultado está em conformidade com outros estudos que apontam que essas políticas não determinam o esforço de inovação desse tipo de empresa. Trata-se, portanto, de outro aspecto que deve ser levado em consideração no que diz respeito à elaboração desse tipo de política pública. Ou seja, é necessário considerar se a concessão de incentivos fiscais para empresas controladas por capitais externos gera, de fato, retornos para o sistema brasileiro de inovação.

A despeito disso, os resultados reafirmam o protagonismo de subsidiárias de empresas multinacionais na atividade inovativa brasileira, dado que essas se destacam, sobretudo, na introdução de produtos e processos novos para o mercado doméstico. Ressalta-se, no entanto, que tal resultado desse ser visto com cautela, uma vez que o desenvolvimento de produtos inovadores por essas empresas é realizado predominantemente em países-sede dessas coorporações.

Dessa forma, foi possível observar no presente trabalho que a política de incentivos fiscais para a promoção da inovação tecnológica apresenta nuances relacionadas tanto ao tipo de tecnologia característica da atividade industrial em questão, quanto à origem do capital controlador da empresa. Sendo esses elementos centrais que devem ser incorporados quando da decisão de concessão desse tipo de benefício frente a um cenário de escassez de recursos e restrição das contas públicas.

\section{Referências}

ARROW, K. J. Economic Welfare and the Allocation of Resources for invention. In Nelson, $\mathrm{R}$ (Ed.). The rate and direction of inventive activity. NBER; Princeton University Press, p. 609629, 1962.

AVELLAR, A. P. M.; ALVES, P. F. Avaliação de impacto de programas de incentivos fiscais à inovação: um estudo sobre os efeitos do PDTI no Brasil. Economia, v. 9, n. 1: p. 142-164, 2008.

AVELLAR, A. P. M; BITTENCOURT, P. F. Política de inovação: instrumentos e avaliação. In: 
RAPINI, M; SILVA, L; ALBUQUERQUE, E. (Org.). Economia da ciência, tecnologia e inovação: fundamentos teóricos e a economia global. Curitiba: Editora Prismas, 2017. p. 571-619, 2017.

BITTENCOURT, P. F; RAUEN, A. T. Políticas de inovação: racionalidade, instrumentos e coordenação. In: RAPINI, M. S; RUFFONI, J.; SILVA, L. A.; ALBUQUERQUE, E. M. (Org.). Economia da ciência, tecnologia e inovação: fundamentos teóricos e a economia global. Belo Horizonte: Cedeplar UFMG, 2020. (Coleção População e Economia).

BRIGANTE, P. C. Uma avaliação da Lei de Informática e seus impactos sobre os gastos empresariais em P\&D nos anos 2000. Revista Brasileira de Inovação, n. 17, v. 1, p. 119-148, 2017.

CALZOLAIO, A. E.; DATHEIN, R. Politicas fiscais de incentivo à inovação: uma avaliação da Lei do Bem. Universidade Federal do Rio Grande do Sul, Faculdade de Ciências Econômicas, n. 15, 2012. Texto para discussão.

CAVALCANTE, L. R. Classificações tecnológicas: uma sistematização. Nota Técnica No. 17. Brasília: Ipea: 2014.

COLOMBO, D. G.; CRUZ, H. N. Impactos da política fiscal de inovação brasileira na composição de investimentos privados e no tipo de inovação. Revista Brasileira de Inovação, v. 17 , n. 2, p. 377-414, 2018.

CHRISTENSEN, J. L. The role of Finance in National System of Innovation. In: LUNDVALL, B. National Systems of Innovation. London: Pinter Publishers, 1992.

FRENKEL, J. Sistemas de apoio fiscal-creditício ao risco tecnológico e à competitividade. Estudo da competitividade da indústria brasileira. Campinas: Unicamp, 1993.

GARCIA, R.; ROSELINO, J. E. Uma avaliação da Lei de Informática e de seus resultados como instrumento indutor de desenvolvimento tecnológico e industrial. Gestão \& Produção, v. 11, n. 2, p. 177-185, 2004.

GREENE, W. Econometric analysis. 4. ed. New Jersey: Prentice Hall, 2000.

GUIMARÃES, E. A. Políticas de inovação: financiamento e incentivos. In: DE NEGRI, J; KUBOTA, L. (Org.). Políticas de Incentivo à Inovação Tecnológica no Brasil. Brasília: IPEA, p. 150216, 2008.

HALL, B. The Assessment: technology policy. Oxford Review of Economic Policy, v. 18, n. 1, p. 1-9, 2002.

HALL, B, H.; LERNER, J. The financing of R\&D and innovation. In: HALL, B; ROSENBERG, N. (Org.). Handbook Of The Economics Of Innovation. Amsterdan: Elsevier, 2010. p. 609-639.

INSTITUTO BRASILEIRO DE GEOGRAFIA E ESTATÍSTICA (IBGE). Pesquisa de Inovação. Rio de Janeiro: IBGE, 2016.

KANNEBLEY JR., S.; SHIMADA, E.; DE NEGRI, F. Efetividade da Lei do Bem no estímulo ao investimento em P\&D: uma análise com dados em painel. Pesquisa e Planejamento Econômico (PPE), v. 46, n. 3, p. 111-145, 2016.

KANNEBLEY JR., S.; PORTO, G. S. Incentivos fiscais à pesquisa, desenvolvimento e inovação no Brasil: uma avaliação das políticas recentes. IDB Publications. Washington, IDB, n. 326, 2012. 
LIBÂNIO, G. A.; FERNANDES, G; DIAS, A. V. C.; SANTOS, U. P.; LONDE. A inovação na indústria brasileira: uma análise a partir dos dados de um painel de empresas da sondagem de inovação. Revista Eletrônica Gestão e Sociedade, v. 13, p. 3.011-3.037, 2019.

MAZZUCATO, M. O Estado empreendedor: desmascarando o mito do setor público vs setor privado. São Paulo: Portfolio-Penguin, 2014.

MAZZUCATO, M.; PENNA, C. R. Beyond market failures: the market creating and shaping roles of state investment banks. Journal of Economic Policy Reform, 19:4, p. 305-326, 2016.

MATIAS-PEREIRA, J. Uma avaliação das políticas públicas de incentivo a inovação tecnológica no Brasil: a Lei do Bem. Parcerias Estratégicas, v. 18, n. 36, p. 221-250, 2015.

METCALFE, S. Equilibrium and Evolutionary Foundations of Competition and Technology Policy: new perspectives on the Division of Labour and Innovation Process. Revista Brasileira de Inovação, v. 2, n. 1, p. 111-145, 2003.

MINISTÉRIO DA CIÊNCIA E TECNOLOGIA - MCT. Relatório Anual da utilização dos Incentivos fiscais ano base 2008 - Lei 11.196105 - Lei do Bem, Brasília, 2009.

NAKAMURA, L. INTANGIBLES: What put the new in the New Economy? Federal Reserve Bank of Philadelphia Business Review, p. 3-16, Jul./Aug.1999.

OLIVEIRA, M. F. O impacto da Lei do Bem: estudo de caso em uma multinacional de cosmético. Dissertação (Mestrado em Administração) - Fundação Getúlio Vargas, São Paulo, 2018.

PACHECO, C. A. As Reformas da política nacional de ciência, tecnologia e inovação no Brasil (19992002). Santiago: CEPAL, 2007.

PENEDER, M. The problem of private under-investment in innovation: A policy mind map. Technovation, v. 28, p. 518-530, 2008.

ROCHA, G.; RAUEN, A. Mais desoneração, mais inovação? Uma avaliação da recente estratégia brasileira de intensificação dos incentivos fiscais a pesquisa e desenvolvimento. Brasília: IPEA, 2018. n. 2.393, p. 46. Texto para discussão.

UNITED NATIONS CONFERENCE ON TRADE AND DEVELOPMENT - UNCTAD. World Investment Report 2019. Geneva: United Nations, 2019.

WILLIAMSON, O. Corporate Finance and Corporate Governance. The Journal of Finance, v. XLIII, n. 3, 567-591, 1988.

WOOLDRIDGE, J. M. Econometric analysis of cross section and panel data. Cambridge: MIT Press, 2002.

ZUCOLOTO, G. F.; SANTANA, B.G.; VELOSO, L. J. P.; KANNEBLEY JR., S. Lei do Bem e produtividade das firmas industriais brasileiras. In: TURCH, L; MORAIS, J. (Org.). Políticas de apoio à inovação tecnológica no Brasil: avanços recentes, limitações e propostas de ações. Brasília: Ipea, 2017.

ZUCOLOTO, G. Origem de capital e acesso aos incentivos fiscais e financeiros à inovação no Brasil. Brasília: IPEA, n. 1.753, 2012. Texto para discussão.

ZUCOLOTO, G. F.; CASSIOLATO, J. E. Desenvolvimento tecnológico por origem de capital: a experiência brasileira recente. Revista Brasileira de Inovação, v. 12, n. 1, p. 133-170, 2013. 


\section{Sobre os autores}

Ulisses Pereira dos Santos-ulisses@cedeplar.ufmg.br

Centro de Desenvolvimento e Planejamento Regional, Universidade Federal de Minas Gerais, Belo Horizonte, MG, Brasil. ORCID: https://orcid.org/0000-0002-6912-0479.

Marcia Siqueira Rapini-msrapini@cedeplar.ufmg.br

Centro de Desenvolvimento e Planejamento Regional, Universidade Federal de Minas Gerais, Belo Horizonte, MG, Brasil. ORCID: https://orcid.org/0000-0002-8035-3003.

Philipe Scherrer Mendes - philipescherrer@gmail.com

Centro de Desenvolvimento e Planejamento Regional, Universidade Federal de Minas Gerais, Belo Horizonte, MG, Brasil. ORCID: https://orcid.org/0000-0002-6481-6928.

\section{Sobre 0 artigo}

Recebido em 02 de setembro de 2019. Aprovado em 09 de dezembro de 2019. 


\section{APÊNDICE}

Tabela A1 Impactos dos incentivos fiscais sobre a inovação de produto das empresas da Sondagem de Inovação - coeficientes estimados - 2010-2016

\begin{tabular}{|c|c|c|c|c|c|c|c|c|c|c|c|c|}
\hline & \multicolumn{6}{|c|}{ Para a Firma } & \multicolumn{6}{|c|}{ Para o Mercado } \\
\hline & \multicolumn{3}{|c|}{ Modelo I } & \multicolumn{3}{|c|}{ Modelo II } & \multicolumn{3}{|c|}{ Modelo III } & \multicolumn{3}{|c|}{ Modelo IV } \\
\hline & O.R. & & $\begin{array}{l}\text { Std. } \\
\text { Err. }\end{array}$ & O.R. & & $\begin{array}{l}\text { Std. } \\
\text { Err. }\end{array}$ & O.R. & & $\begin{array}{r}\text { Std. } \\
\text { Err. }\end{array}$ & O.R. & & $\begin{array}{l}\text { Std. } \\
\text { Err. }\end{array}$ \\
\hline Constante & $-1,069$ & $* * *$ & 0,1480 & $-1,195$ & $* * *$ & 0,1585 & $-2,558$ & $* * *$ & 0,2003 & $-2,690$ & $* * *$ & 0,2163 \\
\hline $\begin{array}{l}\text { Empresas } \\
\text { multinacionais }\end{array}$ & $-0,091$ & & 0,1142 & $-0,057$ & & 0,1163 & 0,476 & $* * *$ & 0,1397 & 0,507 & $* * *$ & 0,1426 \\
\hline $\begin{array}{l}\text { Incentivo às } \\
\text { multinacionais }\end{array}$ & $-0,193$ & & 0,1819 & $-0,225$ & & 0,1877 & $-0,139$ & & 0,2249 & $-0,159$ & & 0,2341 \\
\hline Incentivo concedido & 0,317 & $* * *$ & 0,1077 & & & & 0,109 & & 0,1313 & & & \\
\hline \multicolumn{13}{|c|}{ Incentivo - intensidade tecnológica } \\
\hline Baixa intensidade & & & & 0,270 & & 0,1795 & & & & 0,003 & & 0,2242 \\
\hline $\begin{array}{r}\text { Médio } \\
\text { baixa intensidade }\end{array}$ & & & & 0,137 & & 0,1953 & & & & 0,158 & & 0,2415 \\
\hline $\begin{array}{r}\text { Médio } \\
\text { alta intensidade }\end{array}$ & & & & 0,594 & $* * *$ & 0,1534 & & & & 0,366 & $* * *$ & 0,1846 \\
\hline Alta intensidade & & & & $-0,211$ & & 0,2837 & & & & $-0,582$ & & 0,3755 \\
\hline $\begin{array}{l}\text { Departamento } \\
\text { de P\&D }\end{array}$ & 0,145 & $* *$ & 0,0754 & 0,138 & $*$ & 0,0754 & 0,063 & & 0,0939 & 0,053 & & 0,0942 \\
\hline Doutores em P\&D & 0,000 & & 0,0003 & 0,000 & & 0,0003 & 0,001 & $* * *$ & 0,0003 & 0,001 & $* * *$ & 0,0003 \\
\hline $\begin{array}{l}\text { Aumento dos gas- } \\
\text { tos em Inovação }\end{array}$ & 0,083 & & 0,0992 & 0,071 & & 0,0997 & $-0,073$ & & 0,1229 & $-0,090$ & & 0,1235 \\
\hline $\begin{array}{l}\text { Aumento dos gastos } \\
\text { em P\&D interno }\end{array}$ & 0,396 & $* * *$ & 0,1115 & 0,403 & $* * *$ & 0,1114 & 0,258 & * & 0,1363 & 0,267 & ** & 0,1366 \\
\hline $\begin{array}{l}\text { Aumento dos gastos } \\
\text { em Capacidade Física }\end{array}$ & 0,403 & $* * *$ & 0,0843 & 0,412 & $* * *$ & 0,0847 & 0,276 & $* * *$ & 0,1000 & 0,288 & $* * *$ & 0,1004 \\
\hline \multicolumn{13}{|c|}{ Alta importância dos investimentos em Inovação } \\
\hline $\begin{array}{l}\text { Abrir novos } \\
\text { mercados }\end{array}$ & 0,172 & ** & 0,0876 & 0,169 & $*$ & 0,0880 & 0,445 & $* * *$ & 0,0993 & 0,443 & $* * *$ & 0,0996 \\
\hline $\begin{array}{l}\text { Ganhar participa- } \\
\text { ção no mercado }\end{array}$ & 0,412 & $* * *$ & 0,0768 & 0,425 & $* * *$ & 0,0772 & 0,178 & $*$ & 0,0972 & 0,187 & $*$ & 0,0977 \\
\hline $\begin{array}{l}\text { Inovação de } \\
\text { concorrentes }\end{array}$ & 0,188 & $* *$ & 0,0807 & 0,195 & ** & 0,0810 & $-0,007$ & & 0,0980 & 0,001 & & 0,0983 \\
\hline Pressão de custos & 0,004 & & 0,0754 & 0,006 & & 0,0756 & 0,170 & * & 0,0969 & 0,179 & * & 0,0973 \\
\hline
\end{tabular}


Tabela A1 (continuação)

\begin{tabular}{|c|c|c|c|c|c|c|c|c|}
\hline & & \multicolumn{3}{|c|}{ Para a Firma } & \multicolumn{4}{|c|}{ Para o Mercado } \\
\hline & \multicolumn{2}{|c|}{ Modelo I } & \multicolumn{2}{|c|}{ Modelo II } & \multicolumn{2}{|c|}{ Modelo III } & \multicolumn{2}{|c|}{ Modelo IV } \\
\hline & O.R. & $\begin{array}{l}\text { Std. } \\
\text { Err. }\end{array}$ & O.R. & $\begin{array}{l}\text { Std. } \\
\text { Err. }\end{array}$ & O.R. & $\begin{array}{l}\text { Std. } \\
\text { Err. }\end{array}$ & O.R. & $\begin{array}{l}\text { Std } \\
\text { Err }\end{array}$ \\
\hline Dummy-Ano & Controle & & & & Controle & & & \\
\hline \multicolumn{9}{|c|}{ Dummy CNAE 2.0 - Divisão } \\
\hline $\begin{array}{l}\text { Número de } \\
\text { observações }\end{array}$ & 3919 & & & & 3913 & & & \\
\hline Pseudo R2 & 0,082 & & 0,084 & & 0,060 & & 0,062 & \\
\hline
\end{tabular}

Fonte: Elaboração própria com base na Pesquisa Sondagem de Inovação (2010-2016).

Nota: ${ }^{* *}$ significativo a $1 \%,{ }^{* *}$ significativo a $5 \%$ e ${ }^{*}$ significativo a $10 \%$.

Tabela A2 Impactos dos incentivos fiscais sobre a inovação de processo das empresas da Sondagem de Inovação - Coeficientes estimados - 2010-2016

\begin{tabular}{|c|c|c|c|c|c|c|c|c|c|c|c|c|}
\hline & \multicolumn{6}{|c|}{ Para a Firma } & \multicolumn{6}{|c|}{ Para o Mercado } \\
\hline & \multicolumn{3}{|c|}{ Modelo I } & \multicolumn{3}{|c|}{ Modelo II } & \multicolumn{3}{|c|}{ Modelo III } & \multicolumn{3}{|c|}{ Modelo IV } \\
\hline & O.R. & & $\begin{array}{l}\text { Std. } \\
\text { Err. }\end{array}$ & O.R. & & $\begin{array}{l}\text { Std. } \\
\text { Err. }\end{array}$ & O.R. & & $\begin{array}{l}\text { Std. } \\
\text { Err. }\end{array}$ & O.R. & & $\begin{array}{l}\text { Std. } \\
\text { Err. }\end{array}$ \\
\hline Constante & $-0,734$ & $* * *$ & 0,1483 & $-0,769$ & $* * *$ & 0,1562 & $-2,254$ & $* * *$ & 0,2126 & $-2,198$ & $* * *$ & 0,2246 \\
\hline $\begin{array}{l}\text { Empresas } \\
\text { multinacionais }\end{array}$ & $-0,127$ & & 0,1143 & $-0,099$ & & 0,1163 & 0,422 & $* * *$ & 0,1596 & 0,411 & $* * *$ & 0,1618 \\
\hline $\begin{array}{l}\text { Incentivo às } \\
\text { multinacionais }\end{array}$ & 0,292 & & 0,1826 & 0,201 & & 0,1883 & $-0,278$ & & 0,2518 & $-0,324$ & & 0,2567 \\
\hline Incentivo concedido & $-0,093$ & & 0,1057 & & & & 0,120 & & 0,1452 & & & \\
\hline \multicolumn{13}{|c|}{ Incentivo - intensidade tecnológica } \\
\hline Baixa intensidade & & & & $-0,334$ & * & 0,1740 & & & & $-0,050$ & & 0,2854 \\
\hline $\begin{array}{r}\text { Médio } \\
\text { baixa intensidade }\end{array}$ & & & & 0,076 & & 0,1930 & & & & 0,703 & $* * *$ & 0,2216 \\
\hline $\begin{array}{r}\text { Médio } \\
\text { alta intensidade }\end{array}$ & & & & 0,022 & & 0,1524 & & & & 0,048 & & 0,2064 \\
\hline Alta intensidade & & & & 0,051 & & 0,2931 & & & & $-0,677$ & & 0,5472 \\
\hline $\begin{array}{l}\text { Departamento } \\
\text { de P\&D }\end{array}$ & $-0,133$ & * & 0,0743 & $-0,133$ & * & 0,0744 & 0,095 & & 0,1107 & 0,084 & & 0,1102 \\
\hline Doutores em P\&D & 0,000 & & 0,0003 & 0,000 & & 0,0003 & 0,001 & $* *$ & 0,0003 & 0,001 & $* *$ & 0,0003 \\
\hline $\begin{array}{l}\text { Aumento dos gastos } \\
\text { em Inovação }\end{array}$ & 0,523 & *** & 0,0953 & 0,525 & *** & 0,0956 & 0,269 & ** & 0,1330 & 0,272 & $* *$ & 0,1338 \\
\hline
\end{tabular}


Tabela A2 (continuação)

\begin{tabular}{|c|c|c|c|c|c|c|c|c|c|c|c|c|}
\hline & \multicolumn{6}{|c|}{ Para a Firma } & \multicolumn{6}{|c|}{ Para o Mercado } \\
\hline & \multicolumn{3}{|c|}{ Modelo I } & \multicolumn{3}{|c|}{ Modelo II } & \multicolumn{3}{|c|}{ Modelo III } & \multicolumn{3}{|c|}{ Modelo IV } \\
\hline & O.R. & & $\begin{array}{l}\text { Std. } \\
\text { Err. }\end{array}$ & O.R. & & $\begin{array}{l}\text { Std. } \\
\text { Err. }\end{array}$ & O.R. & & $\begin{array}{l}\text { Std. } \\
\text { Err. }\end{array}$ & O.R. & & $\begin{array}{l}\text { Std. } \\
\text { Err. }\end{array}$ \\
\hline $\begin{array}{l}\text { Aumento dos gastos } \\
\text { em P\&D interno }\end{array}$ & 0,204 & ** & 0,1064 & 0,204 & $* *$ & 0,1066 & 0,429 & *** & 0,1418 & 0,432 & *** & 0,1428 \\
\hline $\begin{array}{l}\text { Aumento dos gastos } \\
\text { em Capacidade Física }\end{array}$ & 0,448 & *** & 0,0826 & 0,445 & $* * *$ & 0,0827 & 0,439 & *** & 0,1110 & 0,443 & *** & 0,1113 \\
\hline \multicolumn{13}{|c|}{ Alta importância dos investimentos em Inovação } \\
\hline $\begin{array}{l}\text { Abrir novos } \\
\text { mercados }\end{array}$ & 0,054 & & 0,0859 & 0,060 & & 0,0860 & 0,244 & ** & 0,1181 & 0,259 & ** & 0,1184 \\
\hline $\begin{array}{l}\text { Ganhar participação } \\
\text { no mercado }\end{array}$ & $-0,023$ & & 0,0757 & $-0,026$ & & 0,0759 & $-0,087$ & & 0,1098 & $-0,105$ & & 0,1100 \\
\hline $\begin{array}{l}\text { Inovação de } \\
\text { concorrentes }\end{array}$ & 0,216 & $* * *$ & 0,0793 & 0,220 & $* * *$ & 0,0795 & 0,109 & & 0,1151 & 0,117 & & 0,1152 \\
\hline Pressão de custos & 0,253 & $* * *$ & 0,0750 & 0,257 & $* * *$ & 0,0751 & 0,232 & $* *$ & 0,1141 & 0,243 & ** & 0,1144 \\
\hline Dummy - Ano & Controle & & & & & & Controle & & & & & \\
\hline \multicolumn{13}{|c|}{ Dummy CNAE 2.0 - Divisão } \\
\hline $\begin{array}{l}\text { Número de } \\
\text { observações }\end{array}$ & 3898 & & & & & & & & & 3919 & & \\
\hline Pseudo R2 & 0,068 & & & 0,072 & & & 0,045 & & & 0,046 & & \\
\hline
\end{tabular}

Fonte: Elaboração própria com base na Pesquisa Sondagem de Inovação (2010-2016).

Nota: ${ }^{* *}$ significativo a $1 \%,{ }^{* *}$ significativo a $5 \%$ e ${ }^{*}$ significativo a $10 \%$. 